\title{
Comparison of Direct Solar Energy to Resistance Heating for Carbothermal Reduction of Regolith
}

\author{
Anthony C. Muscatello ${ }^{1}$ \\ National Aeronautics and Space Administration \\ John F. Kennedy Space Center, FL 32899 \\ Robert J. Gustafson ${ }^{2}$ \\ Orbital Technologies Corporation (ORBITEC ${ }^{T M}$ ), Madison, WI 53717
}

\begin{abstract}
A comparison of two methods of delivering thermal energy to regolith for the carbothermal reduction process has been performed. The comparison concludes that electrical resistance heating is superior to direct solar energy via solar concentrators for the following reasons: (1) the resistance heating method can process $\sim 12$ times as much regolith using the same amount of thermal energy as the direct solar energy method because of superior thermal insulation; (2) the resistance heating method is more adaptable to nearerterm robotic exploration precursor missions because it does not require a solar concentrator system; (3) crucible-based methods are more easily adapted to separation of iron metal and glass by-products than direct solar energy because the melt can be poured directly after processing instead of being remelted; and (4) even with projected improvements in the mass of solar concentrators, projected photovoltaic system masses are expected to be even lower.
\end{abstract}

\section{Nomenclature}

ISRU = in-situ resource utilization

JSC $=$ Johnson Space Center

ORBITEC $=$ Orbital Technologies Corporation

PSI $\quad=$ Physical Sciences Inc.

SBIR = Small Business Innovation Research

NORCAT $=$ Northern Centre for Advanced Technology Inc. (Sudbury, Ontario, Canada)

ISS $\quad=$ International Space Station

\section{Introduction}

$\mathrm{C}$ arbothermal reduction of regolith is an efficient ISRU process for the extraction of oxygen, metallic iron, and silicon, especially when methane is used as the carbon carrier. Regolith is heated to at least $1650^{\circ} \mathrm{C}$ in a methane gas environment. Methane pyrolyzes on the surface of molten regolith, depositing carbon and releasing hydrogen gas. The carbon reduces ilmenite and various silicate minerals in the molten regolith, generating carbon monoxide, metallic iron, and silicon. The carbon monoxide gas bubbles out of the molten regolith and is converted back into methane by combining it with hydrogen in a Sabatier (methanation) reactor. The water produced during the methanation reaction is collected, purified and electrolyzed. The resulting hydrogen is reused in the methanation reaction while the oxygen can be liquefied and stored for use as breathing gas or rocket propellant in space applications. Metallic iron is immiscible in the molten regolith, so it separates into small beads. The silicon remains mixed in the molten regolith.

Traditional approaches to carbothermal reduction of lunar regolith face serious problems due to the high processing temperatures and the corrosive nature of molten regolith. Nearly all high-temperature crucible materials react with the molten regolith and fail during the cooling cycle. Methane injected into the hot-wall reactors pyrolyzes prematurely and carbon deposits plug the gas inlet tubes. ORBITEC developed the direct energy approach to circumvent these problems. In the direct energy approach, concentrated solar energy shines down onto the surface

\footnotetext{
${ }^{1}$ Chemist, Surface Systems Office, NE-S-2, and AIAA Member.

${ }^{2}$ Principal Aerospace Engineer, Space Center, 1212 Fourier Drive, and AIAA Senior Member.
} 
of a regolith bed ${ }^{1}$. Since the regolith has very low thermal conductivity, a pool of molten regolith forms surrounded by unmelted regolith. The unmelted regolith insulates the reactor walls from the molten regolith. The only location in the reactor that is hot enough for methane to pyrolyze is the surface of the molten regolith. ORBITEC initially used lasers to simulate concentrated solar energy. In 2009, PSI developed a system that collects and delivers concentrated solar energy through fiber optic cables to a carbothermal reduction reactor. Figure 1 shows a photograph of the carbothermal reduction reactor and solar concentrator as they appeared during the February 2010 ISRU Field Demonstration on the Mauna Kea volcano ${ }^{2-5}$. End-to-end demonstration of oxygen production and utilization was accomplished using an electrolyzer and a hydrogen storage system from JSC, a fuel cell from the Canadian Space Agency, and a methane/oxygen thruster from JSC. ORBITEC designed, built, and operated the carbothermal reduction reactor, and PSI designed, built, and operated the solar concentrator, both under NASA SBIR Phase 3 contracts. Previously dried volcanic ash (tephra) from the site was provided by both a pneumatic feed system from Honeybee Robotics and by a Load-Haul-Dump Rover from NORCAT.

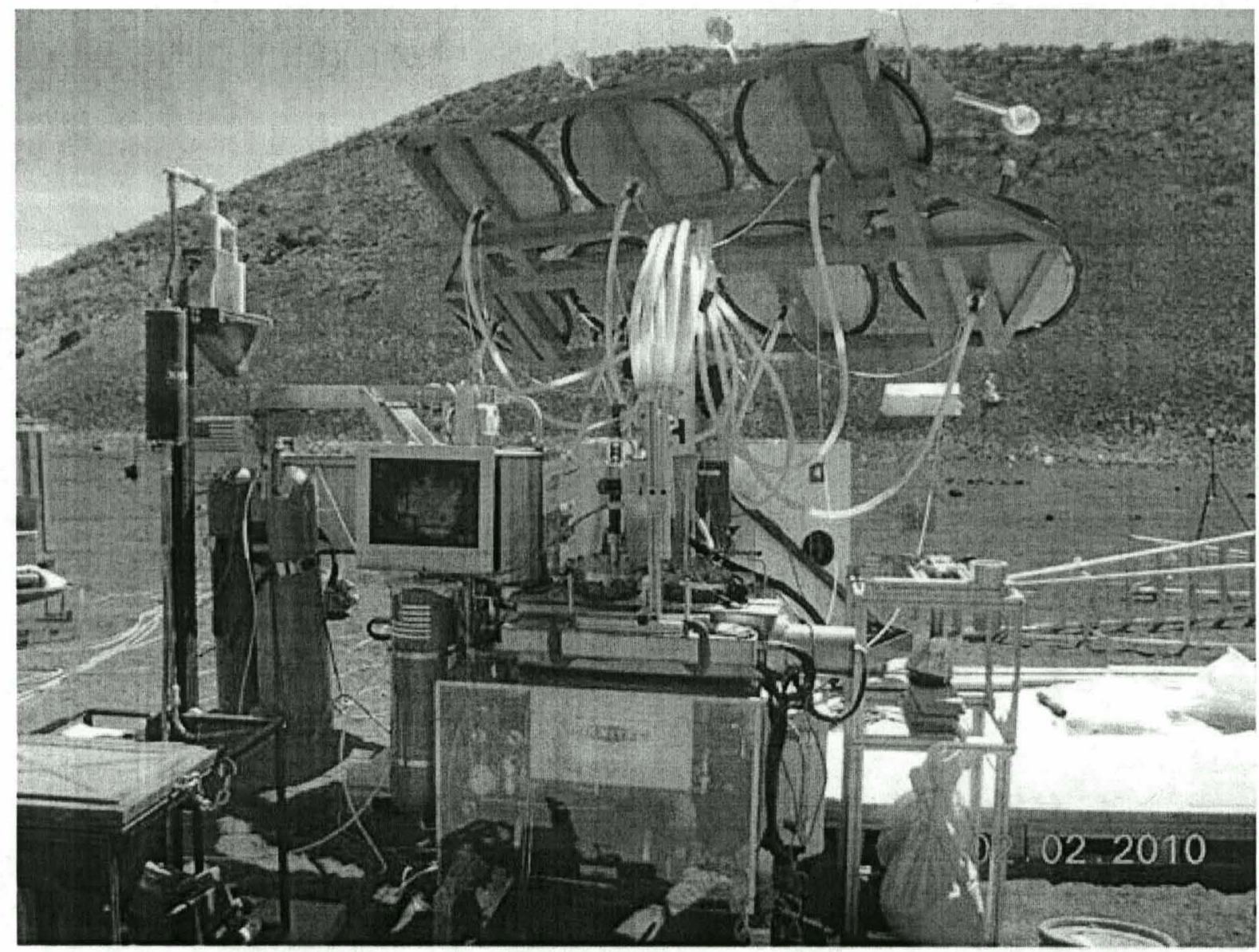

Figure 1. PSI Solar Concentrator (rear) Integrated with the ORBITEC Carbothermal Reduction System (center) with the Honeybee Robotics Pneumatic Tephra Feed Hopper (left).

While the integrated system demonstrated reduction yields of up to $8.1 \%$ by mass, some technical challenges remain for the direct solar energy processing approach. The concentrated solar energy is delivered into the carbothermal reduction reactor using a quartz rod. The temperature of the regolith is controlled by adjusting the distance between the end of the quartz rod and the surface of the regolith. The typical operating distance between the quartz rod and the regolith surface was $3-4 \mathrm{~cm}$. The quartz efficiently transmits the concentrated solar energy into the carbothermal reduction reactor as long as it remains clean. If particulates or deposits accumulate on the quartz rod, the rod will absorb some of the concentrated solar energy leading to rapid heating and eventual failure. The release of carbon monoxide gas from the molten regolith can cause bits of molten regolith to splatter on the end of the quartz rod. The carbothermal reduction process also produces a silica fume by-product that can coat the interior 
surfaces of the reactor, including the quartz rod. A quartz window enclosure was added to the end of the quartz rod to protect it from the potential glass splatter and silica fume deposits. A custom gas nozzle was also added to prevent any deposits from accumulating on the quartz window. Although these modifications were effective at protecting the quartz rod, the quartz window creates an additional energy loss due to Fresnel reflection losses. The direct energy processing approach requires an open path between the quartz rod and the lunar regolith to allow the concentrated solar energy to be delivered. However, this open path also allows a significant amount of energy from the molten regolith to be lost through radiation heat transfer. Since the processing temperatures for carbothermal reduction are high $\left(>1650^{\circ} \mathrm{C}\right)$, losses through radiation heat transfer are significant.

It is important to note that the PSI solar concentrator shown in Figure 1 was developed under a small Phase 3 SBIR contract. Cost compromises drove the solar concentrator system to be relatively large and heavy with a lower efficiency than would possible with current technology. The system would require additional development work to achieve a reasonable flight mass and volume for a possible robotic precursor demonstration mission. Figure 2 shows the relative size of a solar concentrator system to deliver $5.6 \mathrm{~kW}$ of thermal energy to a carbothermal reduction reactor, which is enough energy to produce 1 metric ton of oxygen per year if operated at a lunar polar location with sunlight available $70 \%$ of the time.
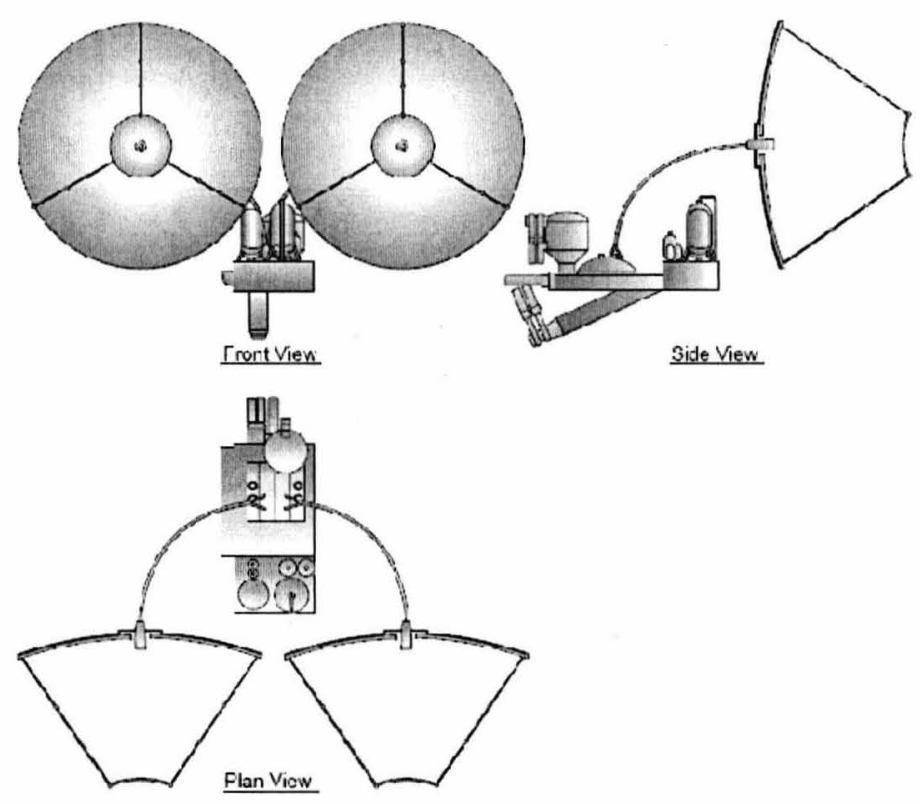

Figure 2. Concept of a Solar Thermal System for a Carbothermal Reduction Process on the Moon. (Nakamura $^{3}$ )

\section{Recent Technical Advances}

To address the technical challenges associated with the direct energy processing approach, ORBITEC is currently developing a new carbothermal reduction reactor technology based on electric resistance heating. ORBITEC recently completed the "Advanced Carbothermal Reactor" Phase 1 SBIR project during which they demonstrated two different methods to electrically heat lunar regolith simulant ${ }^{6}$. Below is the official summary of the Phase 1 project:

\section{Purpose of the Research:}

The overall objective of the Phase 1 effort was to demonstrate the technical feasibility of the Advanced Carbothermal Electric (ACE) Reactor concept. Unlike state-of-the-art carbothermal reactors that use concentrated solar energy and/or laser energy to heat the regolith, the ACE Reactor uses an innovative method to electrically heat the regolith to temperatures over $1800^{\circ} \mathrm{C}$ within a thermally insulated environment, either with or without a crucible. Commercial high-temperature heating elements made from molybdenum disilicide $\left(\mathrm{MoSi}_{2}\right)$ are designed to only operate in oxidizing atmospheres where a protective layer of silicon dioxide $\left(\mathrm{SiO}_{2}\right)$ will form. In Phase 1, the $\mathrm{ACE}$ reactor used $\mathrm{MoSi}_{2}$ heating elements with a 
protective coating to allow them to operate in any type of environment (oxidizing, reducing, or vacuum). The ACE Reactor concept eliminates the problems encountered with traditional carbothermal hot-wall reactors and offers significant advantages over current carbothermal reactor approaches. By eliminating the need for a concentrated solar energy system, the ACE reactor offers a significantly lower system mass and removes the need to keep optical surfaces clean. In addition to efficiently producing oxygen, the ACE reactor separates the processed regolith into metallic iron and a silicate glass that can be formed into structural components or shielding materials.

\section{Description of the Research Carried Out:}

Design requirements were defined for the two prototype ACE Reactors that were built and tested in Phase 1, an ACE Reactor Engineering Unit that will be built and tested in Phase 2, and a ACE Reactor spaceflight unit. A process was developed to apply a protective coating to $\mathrm{MoSi}_{2}$ heating elements. Multiple carbothermal reduction experiments were conducted in the Primary Prototype ACE Reactor using a single crucible. A coated $\mathrm{MoSi}_{2}$ heating element was immersed in molten JSC-1A simulant during a carbothermal reduction experiment in the Alternate Prototype ACE Reactor and destructively analyzed. A second coated $\mathrm{MoSi}_{2}$ heating element was operated under carbothermal reduction conditions while in direct contact with JSC-1A lunar regolith simulant in the Alternate Prototype ACE Reactor. Finally, a preliminary design for an ACE Reactor Engineering Unit was developed.

\section{Phase 1 Result:}

Six carbothermal reduction experiments were performed without any degradation of the crucible due to contact with the molten regolith, the reducing atmosphere, or thermal stresses. The processed regolith was successfully poured out of the crucible at the end of each test allowing the crucible to be reused. A method to separate the metallic iron from the silicate glass in the processed regolith was also demonstrated. Analysis of the coated heating element immersed in the molten regolith during carbothermal reduction processing showed that the coating failed allowing the heating element to react with the melt and degrade. However, the portions of the coated heating element outside the melt region but still in a reducing environment were completely intact. A coated heating element was able to create a melt pool through direct contact with JSC-1A lunar regolith simulant and then be removed from the melt while it was operating. In addition, an ACE Reactor Engineering Unit conceptual design was developed.

\section{Justification for Phase 2 Continuation:}

The Phase I project demonstrated the technical feasibility of the ACE Reactor concept by meeting all of the technical objectives and answering the technical questions. The Primary Prototype ACE Reactor demonstrated that regolith can be processed with $80-85 \%$ less thermal energy than state-of-the-art carbothermal reduction reactors (SOA reactors) with fully reusable hardware (no consumables). This means that an ACE Reactor can process at least 12 times more regolith than an SOA carbothermal reactor given the same thermal energy. The Primary Prototype ACE Reactor demonstrated that the processed regolith can be poured out of a crucible after processing and the crucible reused many times. It also demonstrated that the processed regolith can be separated into metallic iron and silicate glass. The metallic iron or silicate glass can then be poured out of the crucible into a mold to make structural components or shielding materials. The ACE Reactor technology is an efficient, lightweight method for NASA to produce oxygen, iron and glass from regolith to support future human exploration of the Solar System.

The ACE Reactor design allows high-temperature insulation to surround the regolith during processing. As a result, the ACE Reactor has much lower losses through radiation and convection heat transfer than the direct solar energy processing approach. A solid model of the prototype ACE Reactor that was tested in Phase 1 is shown in Figure 3. Figure 4 shows a time lapse series of photographs of molten JSC-1A lunar regolith simulant being poured out of the crucible after the reduction process was completed. This ability allows a single crucible to be reused and allows the molten regolith to be cast into useful shapes. ORBITEC also demonstrated a method to separate the metallic iron from the molten regolith using the prototype ACE Reactor. ORBITEC proposed to develop and test an ACE Reactor Engineering Development Unit under a Phase 2 SBIR project that would serve as a prototype of a flight unit for a future robotic precursor mission. The Phase 2 proposal was recently selected for award by the NASA SBIR program and is expected to begin in January 2011. 

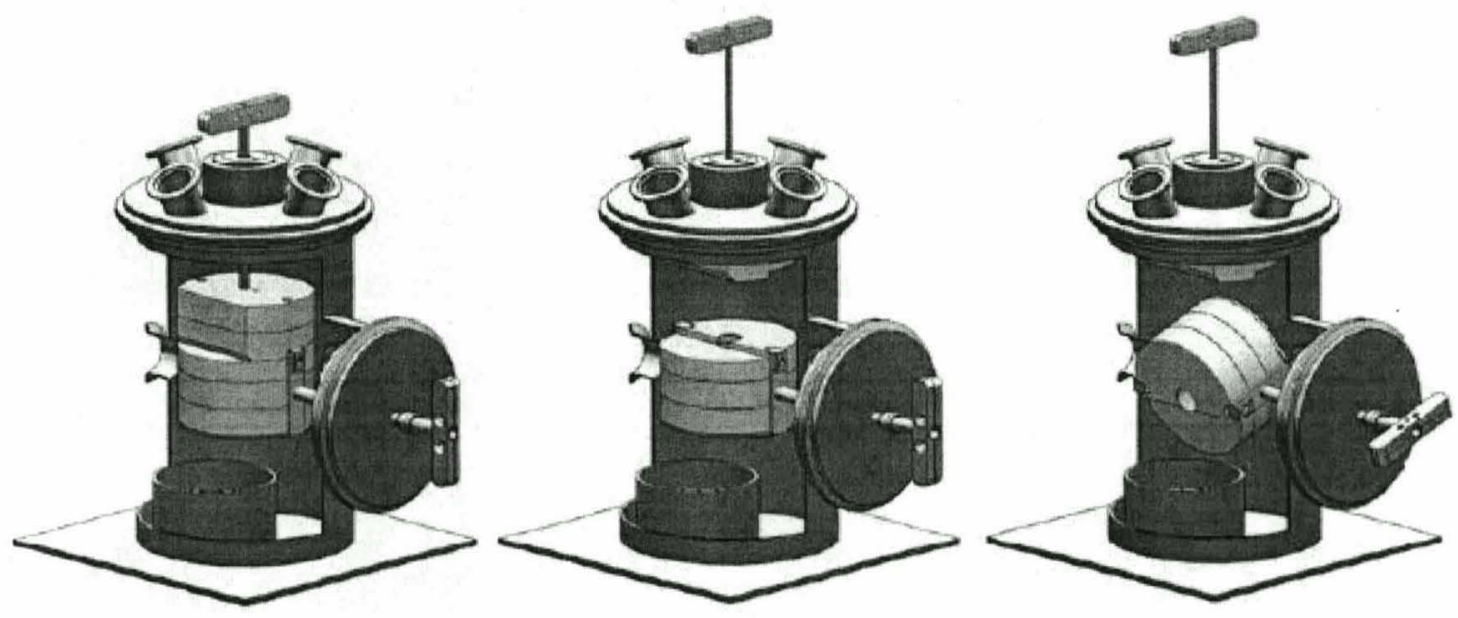

Figure 3. Cutaway View of the Prototype ACE Reactor During Carbothermal Reduction Processing (left), with Insulated Cover Lifted (center), and Molten Regolith Being Poured Out (right).
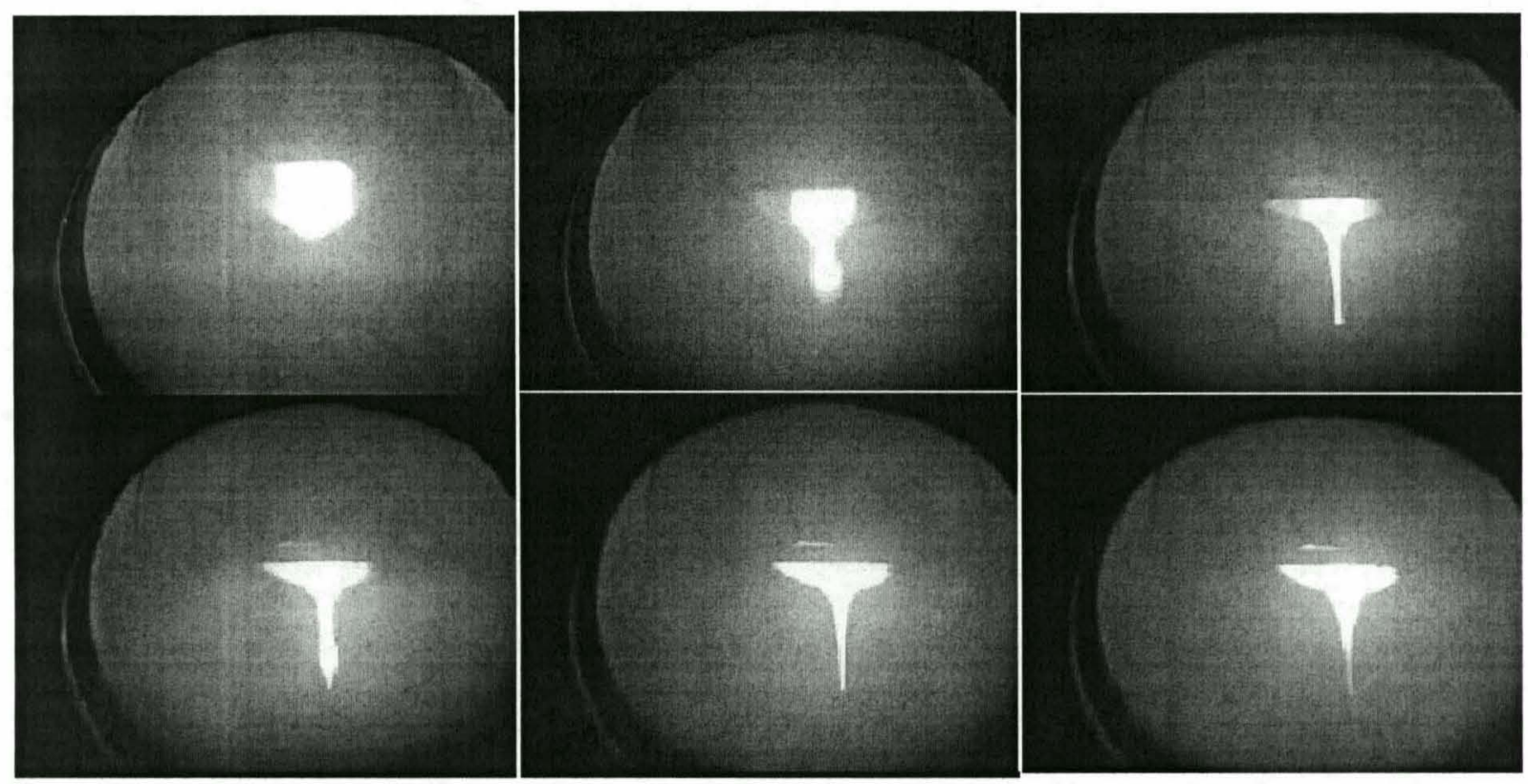

Figure 4. Time Lapse Photographs of the Molten JSC-1A Lunar Regolith Simulant Pouring out of the Crucible in the Prototype ACE Reactor.

\section{Thermal Calculations}

In the Phase 1 ACE Reactor Final Report, ORBITEC performed a simple thermal analysis of the prototype ACE Reactor and compared its results to those for a direct solar energy processing system. The ORBITEC analysis evaluates the radiation, convection, and conduction heat losses for a crucible with molten regolith at $1800^{\circ} \mathrm{C}$, both with and without an insulated cover that has a small opening for gas flow into and out of the crucible. The latter case of no insulated cover is similar to the situation encountered with the direct solar energy processing approach and can be used to compare the relative amounts of energy required to maintain the melt at $1800^{\circ} \mathrm{C}$ in the two scenarios. Note that this simple thermal analysis does not account for the energy required for methane pyrolysis or the energy required to drive the reduction reactions. A summary of the ORBITEC thermal analysis ${ }^{6}$ follows: 


\section{A. Radiation Loss from the Molten Regolith in a 1-Inch Diameter Insulated Crucible}

$\mathrm{q}_{\text {radiation }}=\sigma A \varepsilon\left(\mathrm{T}^{4}-\mathrm{T}_{\infty}{ }^{4}\right)$

$\sigma=5.67 \times 10^{-8} \mathrm{~W} / \mathrm{m}^{2} \mathrm{~K}^{4}$

$\varepsilon=$ emissivity of molten regolith $=0.7$

$\mathrm{A}=$ area of molten regolith $=\pi(0.0127 \mathrm{~m})^{2}=0.000506 \mathrm{~m}^{2}$

$\mathrm{T}=$ temperature of molten regolith $=2073 \mathrm{~K}$

With no insulated cover, $\mathrm{T}_{\infty}=\sim 300 \mathrm{~K}$

$\mathrm{q}_{\text {radiation }}=370.7 \mathrm{~W}$

With an insulated cover, $\mathrm{T}_{\infty}=\sim 2073 \mathrm{~K}$ after reaching steady state.

$\mathrm{q}_{\text {radiation }}=>0 \mathrm{~W}$ (after reaching steady state conditions)

If the insulated cover has a hole 0.25 inches $\left(0.00635 \mathrm{~m}^{2}\right)$ in diameter, then the radiation loss would be $6.25 \%$ of the case with no insulated cover.

$$
\mathrm{q}_{\text {radiation }}=0.0625(370.7 \mathrm{~W})=23.2 \mathrm{~W}
$$

\section{B. Total Energy Loss from the Molten Regolith in an Insulated Crucible}

$$
\begin{aligned}
& \mathrm{q}_{\mathrm{conduction}}=\kappa \mathrm{AdT} / \mathrm{dx} \\
& \mathrm{dT}=2073 \mathrm{~K}-303 \mathrm{~K}=1770 \mathrm{~K} \\
& \kappa=0.39 \mathrm{~W} / \mathrm{mK} \text { for ceramic insulation } \\
& \mathrm{dx}=0.0508 \mathrm{~m} \\
& \mathrm{q}_{\mathrm{conduction}}=41.3 \mathrm{~W} \\
& \mathrm{~A}=0.003039 \mathrm{~m}^{2} \text { for crucible surface area } \\
& \text { ( } 1 \text { inch diameter, } 1 \text { inch height) } \\
& \mathrm{q}_{\text {convection }}=\mathrm{h}_{\mathrm{r}}(\mathrm{dT}) \mathrm{A} \\
& \mathrm{h}_{\mathrm{r}}=\sim 25, \mathrm{dT}=1770 \mathrm{~K} \text { (cover off), } \mathrm{A}=0.000506 \mathrm{~m}^{2} \text { for melt surface area } \\
& \mathrm{q}_{\text {convection }}=22.4 \mathrm{~W} \text { (with insulated cover off) } \\
& \mathrm{q}_{\text {radiation }}=370.7 \mathrm{~W} \text { (with insulated cover off) } \\
& \mathrm{q}_{\text {radiation }}=23.2 \mathrm{~W} \text { (with insulated cover on and } 0.25 \text { inch diameter hole in cover) }
\end{aligned}
$$

$$
\mathrm{q}_{\text {total }}=\mathrm{q}_{\mathrm{conduction}}+\mathrm{q}_{\mathrm{convection}}+\mathrm{q}_{\mathrm{radiation}}=41.3+22.4+370.7=434.4 \mathrm{~W}
$$

With insulated cover on:

$$
\begin{aligned}
& \mathrm{q}_{\mathrm{total}}=\mathrm{q}_{\text {conduction }}+\mathrm{q}_{\text {convection }}+\mathrm{q}_{\text {radiation }}=41.3+(0 \text { to } 22.4)^{*}+23.2=64.5 \text { to } 86.9 \mathrm{~W} \\
& \quad * \text { Depends on the amount of convective cooling. }
\end{aligned}
$$

\section{Energy Loss With and Without the Insulated Cover}

$$
\begin{aligned}
\mathrm{q}_{\text {cover off }}= & 434.4 \mathrm{~W} \\
\mathrm{q}_{\text {cover on }}= & 64.5 \text { to } 86.9 \mathrm{~W} \\
& 64.5 \mathrm{~W} \text { if we assume no convective cooling } \\
& 86.9 \mathrm{~W} \text { if we assume full convective cooling }
\end{aligned}
$$




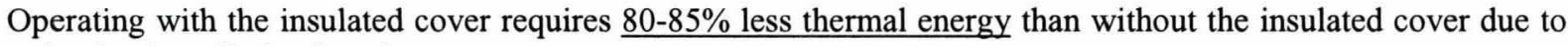
the reduction in radiation heat loss.

\section{2-inch diameter, 2-inch height crucible @ 1800 $\mathrm{C}$ Simulant}

1-inch diameter, 1-inch height crucible holds 17-24 g JSC-1A

2-inch diameter, 2-inch height crucible holds 144-196 g JSC-1A

$\mathrm{q}_{\text {conduction }}=115.3 \mathrm{~W}$

$\mathrm{q}_{\mathrm{convection}}=89.7 \mathrm{~W}$ (with insulated cover off)

$\mathrm{q}_{\text {radiation }}=1,484 \mathrm{~W}$ (with insulated cover off)

$\mathrm{q}_{\text {radiation }}=92.75 \mathrm{~W}$ (with insulated cover and 0.25 inch hole)

With insulated cover off:

$\mathrm{q}_{\text {total }}=\mathrm{q}_{\text {convection }}+\mathrm{q}_{\text {radiation }}+\mathrm{q}_{\text {radiation }}=115.3+89.7+1,484=1,689 \mathrm{~W}$

With insulated cover on:

$\mathrm{q}_{\text {total }}=\mathrm{q}_{\mathrm{convection}}+\mathrm{q}_{\text {radiation }}+\mathrm{q}_{\text {radiation }}=115.3+(0 \text { to } 89.7)^{*}+92.75=208$ to $297.5 \mathrm{~W}$

1-inch diameter, 1-inch height crucible (17-24 g JSC-1A):

$$
\mathrm{q}_{\mathrm{cover} \mathrm{off}}=434.4 \mathrm{~W}
$$

2-inch diameter, 2-inch height crucible (144-196 g JSC-1A):

$$
\mathrm{q}_{\text {cover on }}=208 \text { to } 297.5 \mathrm{~W}
$$

Therefore, the use of an insulated cover in the ACE Reactor allows more than 8.5 times the amount of JSC-1A simulant to be held at $1800^{\circ} \mathrm{C}$ with less energy than the case where no insulated cover is used.

\section{E. Consider a crucible with a diameter of 2.25 inches}

It will hold 204.7-277.8 $\mathrm{g}$ of JSC-1A simulant depending on the density.

$$
\begin{aligned}
& \mathrm{q}_{\text {radiation }}=117.5 \mathrm{~W} \text { (with insulated cover having a } 0.25 \text { inch diameter hole) } \\
& \mathrm{q}_{\text {convection }}=113.5 \mathrm{~W} \text { (without an insulated cover) } \\
& \mathrm{q}_{\text {conduction }}=174.3 \mathrm{~W} \\
& \mathrm{q}_{\text {total }}=405.3 \mathrm{~W} \text { (cover on) }
\end{aligned}
$$

Therefore, at least 12 times more JSC-1A simulant can be held at $1800^{\circ} \mathrm{C}$ in the ACE reactor with a cover than without the insulated cover (analogous to the direct solar energy processing approach).

For a small $(2.54 \mathrm{~cm}$ outer diameter) crucible, the radiation loss is $370.7 \mathrm{~W}$ without a cover and only $23.2 \mathrm{~W}$ with a cover with a $0.25 \mathrm{~cm}$ hole, a reduction of $93.75 \%$. Taking into account conduction and convection losses results in a total loss of $434.4 \mathrm{~W}$ without a cover and 64.5-86.9 W with a cover (depending on the actual convection losses), the use of the insulated cover results in an $80-85 \%$ reduction in the thermal energy required. The ORBITEC analysis goes on to consider how much more regolith may be processed with a cover for the approximately the same 
amount of thermal energy as the no cover situation. It concludes that a crucible with a diameter and height of 5.72 $\mathrm{cm}$ will require $405.3 \mathrm{~W}$ or less (including radiation, convection, and conduction losses) to maintain $1800^{\circ} \mathrm{C}$, whereas a solar concentrator-heated open crucible with a diameter and height of only $2.54 \mathrm{~cm}$ would require 434.4 W. The $5.74 \mathrm{~cm}$ crucible would hold 204.7-277.8 g of JSC-1A lunar simulant (depending on the compaction of the regolith) while the $2.54 \mathrm{~cm}$ crucible would contain only $17-24 \mathrm{~g}$ of simulant, or a factor of $\sim 12$ times more regolith processed with the same energy or less, based on the average masses.

This very large increase in the mass of material processed per watt of thermal energy is a tremendous advantage for the fully insulated (electrically heated crucible-based) system. However, this calculation does not include the energy required to pyrolyze the methane and react carbon with various minerals in the regolith. Berggren et al. ${ }^{7}$ have listed the enthalpies of the following relevant reactions (these reactions are simplifications of the actual chemistry of lunar regolith which actually contains ilmenite $\left(\mathrm{FeTiO}_{2}\right)$ and various silicates, but the given enthalpies of reaction will be accurate enough for this analysis):

- Carbothermal reduction:

$$
\begin{array}{ll}
\mathrm{FeO}+\mathrm{C}=\mathrm{Fe}+\mathrm{CO} & \Delta \mathrm{H}=156.7 \mathrm{~kJ} / \mathrm{mole} \\
\mathrm{SiO}_{2}+2 \mathrm{C}=\mathrm{Si}+2 \mathrm{CO} & \Delta \mathrm{H}=689.8 \mathrm{~kJ} / \mathrm{mole}
\end{array}
$$

- Carbon deposition (methane decomposition) ${ }^{8}$ :

$$
\mathrm{CH}_{4}=\mathrm{C}+2 \mathrm{H}_{2} \quad \Delta \mathrm{H}=75.6 \mathrm{~kJ} / \mathrm{mole}
$$

Nevertheless, the ORBITEC comparison is valid because the amount of energy supplied to drive these reactions would be the same no matter how the energy is supplied per mole of reactants. For the above case of the crucible holding an average of $241 \mathrm{~g}$ of regolith and assuming a typical lunar composition of $10.5 \mathrm{wt} \%$ of $\mathrm{FeO}$ equivalent and $47.3 \mathrm{wt} \%$ of $\mathrm{SiO}_{2}$ equivalent ${ }^{9}$, we can calculate the energy required to reduce all the $\mathrm{FeO}$ and enough $\mathrm{SiO}_{2}$ to yield $15 \%$ oxygen $(36.2 \mathrm{~g})$. This amount of oxygen equals 2.26 moles, which would require 2.26 moles of carbon or methane.

- Decomposition of methane $=75.6 \mathrm{~kJ} / \mathrm{mole} \times 2.26$ moles $=$

- Reduction of $25.3 \mathrm{~g}$ or 0.352 moles of $\mathrm{FeO}=$

- Reduction of 1.91 moles of $\mathrm{SiO}_{2}=$

- Total $=$
$170.9 \mathrm{~kJ}$

$55.5 \mathrm{~kJ}$

$1,316 \mathrm{~kJ}$

$1,540 \mathrm{~kJ}$

Comparing these results requires converting the heat loss wattage to $\mathrm{kJ}$ by multiplying by the time required for the reaction. The standard time for the carbothermal reduction process using solar energy is $80 \mathrm{~min}(4,800 \mathrm{sec})$. Although this time has not been optimized, we will use it as a reference point that is close enough for the comparison at hand. Thus, the amount of power required to maintain the melt at $1800^{\circ} \mathrm{C}(405.3 \mathrm{~W})$ for $4,800 \mathrm{sec}$ is $1.95 \times 10^{6} \mathrm{~W}$-sec or $1,950 \mathrm{~kJ}$ since $1 \mathrm{~W}$-sec $=1 \mathrm{~J}$. It may be surprising that the energy required to reduce the regolith is comparable to the energy required to keep it at the reaction temperature, but there is substantial energy required to decompose the methane and much more required to reduce the silicate minerals. However, remember that this is the case only for the highly efficient resistance-heated crucible. For the less efficient direct energy processing case, the energy required to maintain the reaction temperature will dominate and will be on the order of $23,300 \mathrm{~kJ}$ using the 12 -fold increase calculated above. The energy required to drive the chemical reactions must be considered when sizing heating elements for crucible-based processing.

\section{Energy Conversion Efficiencies}

Another factor that should be considered in comparing solar or direct heating to resistance heating is the efficiency of converting the ultimate power source into thermal energy being used to drive the carbothermal reaction, both maintaining the temperature and supplying chemical energy. For the solar concentrator, the currently demonstrated efficiency is $\sim 33 \%$ in converting incident solar flux into delivered power. Nakamura ${ }^{4}$ has estimated that a space-rated system could be $76 \%$ efficient. Although resistance heating elements are nearly $100 \%$ efficient in converting electrical energy into heat, the full efficiency depends of how the electricity is generated. For a straightforward comparison of the solar concentrator to resistance heating, we can estimate the efficiency by using solar cells to convert sunlight into electricity. But efficiency alone is not a sufficient metric. A more realistic mode 
of comparison is the power generated per mass $(\mathrm{kg})$ of the system. The current solar concentrator mass for the system demonstrated on Mauna Kea is 25 times that of the photovoltaic systems on the International Space Station $(28.4 \mathrm{~W} / \mathrm{kg})$. Using this value gives $1.14 \mathrm{~W} / \mathrm{kg}$ for the current solar concentrator.

For the resistance heating approach, the total energy required is $727 \mathrm{~W}$ for carbothermal reduction (over $80 \mathrm{~min}$ ) and $405 \mathrm{~W}$ for heating for a total of $1,132 \mathrm{~W}$. Using the ISS solar arrays as a reference would require a $45.6 \mathrm{~kg}$ photovoltaic system. It should be noted that the ISS arrays are based on outdated technology and that much more efficient systems are becoming available, even as high as $1000 \mathrm{~W} / \mathrm{kg}^{10}$. For the solar concentrator system, a 12-fold increase in power results in 4,864 W for heating regolith and $727 \mathrm{~W}$ for carbothermal reduction for a total of 5,591 $\mathrm{W}$, leading to a $4,904 \mathrm{~kg}$ system using current technology. This is rather unfair since some efficiency improvements are realized when using the seven melt system envisioned for development until recent redirection of NASA's exploration plans. Using those improvements, such as heating of neighboring melts by other melts and much lighter structural materials for the solar concentrator, a $5.6 \mathrm{~kW}$ thermal solar concentrator system was estimated to be sufficient to produce $1,000 \mathrm{~kg}$ of oxygen per year at $70 \%$ operating time at a lunar base. Nakamura ${ }^{3}$ estimated a 5.9 $\mathrm{kg} / \mathrm{kW}$ or $169 \mathrm{~W} / \mathrm{kg}$ system. Using this value in the above analysis gives a $33.1 \mathrm{~kg}$ system, which compares well to the ISS-based estimate of $45.6 \mathrm{~kg}$. Upgrading the photovoltaic array to currently available space technology at 80 $100 \mathrm{~W} / \mathrm{kg}^{11}$ gives a large advantage to the resistance heater system at $13.0 \mathrm{~kg}$.

\section{Technical Issues}

Several technical issues remain to be resolved for both heating methods before they can be successfully applied in a carbothermal regolith reduction reactor. For resistance heating, many more successful test runs are needed to reduce the technical risks of the process in an ACE Reactor Engineering Unit, as is planned by ORBITEC during the follow-on Phase 2 SBIR project. For future scale-up, the amount of residual regolith remaining in the crucible between processing batches needs to be determined and found to not be a significant hindrance to overall process efficiency. The durability and operating lifetime of the crucible and the coated heating elements also needs to be established. Control of carbon deposition on the melt and nowhere else through methane decomposition needs to be demonstrated reliably. Casting of molten regolith and the separation of iron metal product also requires further development. Optimal operating conditions (duration, oxygen yield, minimization of carbon losses) should be examined, using what is already known from prior studies. It should be verified that the crucible will not form alloys with iron or with silicon under typical carbothermal reduction conditions. The combined mass of the resistance heater/crucible system and photovoltaic array should be compared to a direct energy solar concentrator/carbothermal reduction system with the same oxygen production capacity to determine which has better mass performance.

For the solar concentrator system, the upgrades proposed by Nakamura ${ }^{3}$ need to be demonstrated to show their validity, although no funding for such a demonstration is currently available. The mass reductions identified also need to be demonstrated. Demonstration of a system of a small size appropriate for a robotic precursor mission, if feasible, would be useful for comparison to the resistance heater system.

\section{Conclusions}

Comparison of the direct solar energy processing approach and electric resistance heating is difficult since the two technologies are at different Technical Readiness Levels (TRLs) and different assumptions can be made on improvements in both systems. The electric resistance heating approach is currently at TRL 3-4 (laboratory validation) while the direct solar energy processing approach is at TRL 5 (integrated field demonstration). Based on thermal calculations, the crucible/resistance heating method appears to be preferred in oxygen production efficiency compared to the current solar concentrator system. However, the solar concentrator system can be projected to be comparable to the resistance heating technology when coupled to current TRL 9 photovoltaic arrays. However, reasonable improvements in photovoltaic technologies would make the resistance heating system the clear choice. Because of the cancellation of the Constellation Project, the likelihood of a lunar base is very low in the next decade or so. However, there will be opportunities for exploration robotic precursor missions. The electric resistance heating approach appears to be a better candidate for a robotic precursor mission because of: (1) its inherit simplicity, (2) the fact that the spacecraft would already have photovoltaic arrays that could be enlarged to provide power, and (3) the versatility of the resistance system in providing the capability to produce metallic iron and usable shapes from casting melts. If other uses for the solar concentrator system can be found, such as hybrid concentrator/photovoltaics, its development should continue. For carbothermal reduction, the electric resistance heating approach is more promising and should be viewed as a higher priority for near-term development. 


\section{Acknowledgments}

The authors gratefully acknowledge that some of the work reported here was supported by the NASA ISRU Project Office and the NASA SBIR Program. Kris Lee of the NASA Johnson Space Center served as the COTR for the NASA SBIR Phase 1 ACE Reactor project. Work demonstrating the use of the solar concentrator to drive the carbothermal reduction reaction is currently supported through a Phase 3 SBIR contract to ORBITEC from the NASA Kennedy Space Center where Dr. Anthony Muscatello serves as the COTR.

\section{References}

'Gustafson, R.J., White, B.C. and Fidler, M.J., "Demonstrating Carbothermal Reduction of Lunar Regolith Using Concentrated Solar Energy," AIAA 2009-6476, AIAA SPACE 2009 Conference \& Exposition, 14 - 17 September 2009 , Pasadena, California.

${ }^{2}$ Gustafson, R.J., White, B.C. and Fidler, M.J., "Analog Field Testing of the Carbothermal Regolith Reduction Processing System," AIAA 2010-8901, AIAA SPACE 2010 Conference \& Exposition, 30 August - 2 September 2010, Anaheim, California.

${ }^{3}$ Nakamura, T., Van Pelt, A.D., and Smith, B.K., "Solar Thermal Power System for Oxygen Production from Lunar Regolith," AIAA 2009-660, 47th AIAA Aerospace Sciences Meeting Including The New Horizons Forum and Aerospace Exposition, 5 - 8 January 2009, Orlando, Florida.

${ }^{4}$ Nakamura, T. and Smith, B.K., "Solar Thermal Power System for Oxygen Production from Lunar Regolith," AIAA 20096509, AIAA SPACE 2009 Conference \& Exposition, 14 - 17 September 2009, Pasadena, California.

${ }^{5}$ Nakamura, T. and Smith, B.K., "Solar Thermal Power System for Lunar ISRU Applications: Result of ISRU Analog Test, Mauna Kea, HI," AIAA 2010-8902, AIAA SPACE 2010 Conference \& Exposition, 30 August - 2 September 2010, Anaheim, California.

${ }^{6}$ ORBITEC, "Advanced Carbothermal Electric (ACE) Reactor," NASA SBIR Phase 1 Report, Contract Number: NNX10RA67P, Orbital Technologies Corporation - Madison, WI, 23 July 2010.

${ }^{7}$ Berggren, M., Zubrin, R., Carrera, S., Rose, H., and Muscatello, S., "Carbon Monoxide Silicate Reduction System (COSRS)," Space Resources Roundtable VII: LEAG Conference on Lunar Exploration, October 26, 2005 (http://www.lpi.usra.edu/meetings/leag2005/presentations/wed_am/04 berggren.pdf [cited 28 November 2010]).

${ }^{8}$ Muradov,, N., Smith, F., and Raissi, A., "Catalytic Dissociation of Hydrocarbons: a Route to CO-free Hydrogen," 15 th Annual Saudi-Japanese Symposium, Catalysts in Petroleum Refining \& Petrochemicals, Dhahran, Saudi Arabia, November 2728, 2005 (URL http://www.kfupm.edu.sa/catsymp/Symp15th/10\%20Muradov.pdf [cited 28 November 2010])

${ }^{9}$ McKay, D., Carter, J., Boles, W., Allen, C., and Allton, J., “JSC-1: A New Lunar Soil Simulant," Engineering, Construction, and Operations in Space IV, American Society of Civil Engineers, pp. 857-866, 1994

${ }^{10}$ Piszczor, Jr., M.F., O’Neill, M.J., Eskenazi, M., and Brandhorst, H., "Stretched-Lens Photovoltaic Concentrator Arrays for NASA's Moon/Mars Exploration Missions,” 2nd International Energy Conversion Conference (IECEC), August 16-19, 2004, Providence, Rhode Island.

${ }^{11}$ A.K. Reed and C.H.J. Willenberg, 2004, "Early Commercial Demonstration of Space Solar Power Using Ultra-Lightweight Arrays", IAC-07-C3.2.04.

(URL http://www.spacefuture.com/archive/early commercial demonstration of space solar_power using ultra lightweight arrays.sh $\underline{\mathrm{tml}}$ [cited 28 November 2010]) 